\title{
Conceptual design of a polymer composite automotive bumper energy absorber
}

\begin{abstract}
In this paper, a study of conceptual design of fibre reinforced epoxy composite bumper absorber is presented. This study describes the use of the composite in energy absorption in car bumper as a pedestrian energy absorber. The systematic exploitation of proven ideas or of experience was used to generate the ideas and the most suitable idea was followed as a guide for conceptual design. The absorber was analyzed experimentally and the data from these experiments were used to decide on the number of energy absorber to be used in the design. Final design of the composite energy absorber in elliptical shape with two slots at both ends was considered. The method of fixing the energy absorber to the fascia and bumper was also studied.
\end{abstract}

Keyword: Automotive bumper system; Composite materials; Conceptual design; Energy absorber 